\title{
Conjugative Plasmid Transfer in the Biofilm Formed by Enterococcus faecalis
}

\author{
Takumi Kajiura, ${ }^{*},{ }^{a}$ Hideki Wada, ${ }^{a}$ Kenji Ito ${ }^{a}$ Yojiro Anzai, ${ }^{b}$ and Fumio Kato ${ }^{b}$ \\ ${ }^{a}$ Department of Research and Development, Yoshida Pharmaceutical Co., Ltd., 951 Minami-iriso, Sayama, Saitama 350-1316, Japan \\ and ${ }^{b}$ Department of Microbiology, Faculty of Pharmaceutical Sciences, Toho University, 2-2-1 Miyama, Funabashi, Tokyo 274-8510, \\ Japan
}

(Received December 26, 2005; Accepted March 24, 2006)

\begin{abstract}
Enterococcus faecalis (E. faecalis) ATCC51299 used as a control in screening for high-level aminoglycoside resistance in enterococci was observed to transfer plasmids to the clinically isolated E. faecalis strain 4437 in a broth medium. From a mixed culture of strain ATCC51299 and strain 4437, transconjugants were obtained not only from the planktonic phase but also from biofilm. Plasmid transfer frequency was approximately one order higher among cells in the biofilm than among those in the planktonic phase. When the biofilm formed by the recipient strain $E$. faecalis 4437 was inoculated with the donor strain E. faecalis ATCC51299, correlations were observed between the number of donor cells and transconjugants, and the number of donor cells and transfer frequency in the biofilm $(r=$ $0.99,0.98$, respectively). In addition, the transfer frequency in biofilm remained constant after 9-hr incubation, while transfer frequency in the planktonic phase decreased with incubation time. These results suggest that the biofilm formed by enterococci on surfaces gives rise to efficient gene transfer.
\end{abstract}

Key words — enterococci, biofilm, conjugative transfer, plasmid

\section{INTRODUCTION}

Enterococci are normal probiotic bacteria in the human and animal intestinal flora. However, these bacteria are capable of causing disease as opportunistic pathogens. ${ }^{1)}$ Enterococci are intrinsically rugged organisms endowed with traits such as growth in the temperature range between 10 and $45^{\circ} \mathrm{C}$, growth in broth with $6.5 \% \mathrm{NaCl}$ or at $\mathrm{pH} 9.6$, and the ability to survive at $60^{\circ} \mathrm{C}$ for 30 min. ${ }^{2)}$ Enterococci are also able to survive on dry environmental surfaces from 7 days to 4 months. ${ }^{3)}$ They are intrinsically resistant to many antibiotics and readily acquire resistance to most antibiotics. ${ }^{4,5)}$

Vancomycin-resistant enterococci (VRE) were first detected in Europe in 1986, ${ }^{6,7)}$ and since then VRE have spread rapidly, predominantly in the veterinary field in Europe and in medical fields in the U.S.A. ${ }^{5)}$ In $2000,26.3 \%$ of the intensive care unit enterococcal isolates reported to the US National

*To whom correspondence should be addressed: Department of Research and Development, Yoshida Pharmaceutical Co., Ltd., 951 Minami-iriso, Sayama, Saitama 350-1316, Japan. Tel.: +814-2957-2346; Fax: +81-4-2957-7698; E-mail address: kajiura@ yoshida-pharm.co.jp
Nosocomial Infections Surveillance system (NNIS) were resistant to vancomycin. ${ }^{8)}$ The Society for Healthcare Epidemiology of America (SHEA) guidelines recommends rigorous infection control practices designed to prevent transmission for the control of VRE infections. ${ }^{3)}$ In Japan, the first clinical isolate of VRE was detected in 1997,9) and although the number of VRE infections has been sporadic and small thus far, the spread of VRE in medical, food, and veterinary fields will be a future concern.

The complete genome sequence of vancomycinresistant Enterococcus faecalis (E. faecalis) V583 revealed that more than $25 \%$ of the genome consists of possible mobile or foreign DNA. The apparent propensity for the acquisition of mobile elements essentially contributes to the rapid acquisition and dissemination of drug resistance in the enterococci. ${ }^{10)}$ Enterococci can acquire resistance to antibiotics either by mutation or by acquisition of plasmids or transposons. $\left.{ }^{4}\right)$ Three different conjugative transfer systems have been reported in enterococci. ${ }^{2,11)}$ The first type of transfer relates to broad host-range plasmids, generally dependent on cell contact on solid media, and is inefficient in broth. The second type of transfer relates to narrow host-range plasmids that transfer at a high frequency in broth. These plas- 
mids respond to clumping-inducing agents, or "pheromones" from recipient cells by expressing an aggregation substance. The third type of conjugative system in enterococci relates to conjugative transposons. Transfer by this mechanism occurs at a low frequency on solid media.

In nutrient-limited ecosystems, such as an aquatic environment, bacteria tend to attach to a surface and begin biofilm formation. ${ }^{12)} \mathrm{A}$ biofilm can be defined simply and broadly as a community of microorganisms attached to a surface. ${ }^{13)}$ Biofilm formation is regulated at four main steps: surface attachment, microcolony formation, depth of the mature biofilm, and biofilm architecture. Occasionally, biofilm-associated bacteria detach from the biofilm matrix. ${ }^{14)}$ Obviously, more than $99 \%$ of bacteria grow in biofilms on a wide variety of surfaces (i.e., biotic or abiotic).${ }^{15)}$ Bacteria are able to colonize and produce biofilms on surfaces including rocks in streams, ship hulls, and industrial water pipelines, as well as contact lenses and many varieties of biomedical implants and transdermal devices. ${ }^{12,15,16)}$ Resistance to antimicrobials is a general trait of all biofilms that are the major cause of uncomfortable infections. ${ }^{17-19)}$ Biofilms may be responsible for $65 \%$ of all bacterial infections. ${ }^{20)}$

E. faecalis isolates are reported to establish significantly more biofilms than E. faecium isolates. ${ }^{21)}$ Biofilm-forming E. faecalis strains can also survive in peritoneal macrophages for longer periods than nonbiofilm-forming strains. ${ }^{22}$ Endocarditis isolates of $E$. faecalis produced significantly more biofilms than nonendocarditis isolates. ${ }^{23)}$ Recent research has indicated that the $f s r$ two-component signaling system ( $f s r$ quorum-sensing system) is important for biofilm formation, and in this report, gelatinase was the only entity downstream from $f s r$ signaling which mediated biofilm formation. ${ }^{24)}$ Those findings suggest that the ability to form biofilms is associated with the pathogenicity of enterococci.

Gene transfer by conjugation is considered to be one of the most of important mechanisms for the establishment of new genetic traits in various environments and plays an important role in the spread of genetic traits. ${ }^{25,26)}$ There are many reports of efficient plasmid transfer both in natural and in laboratory-based biofilm systems. ${ }^{27)}$ However, there are few reports on plasmid transfer in biofilm systems of enterococci, and transconjugation between enterococci in biofilms merits investigation. Here we report on transconjugation between $E$. faecalis in a planktonic phase and in biofilm.

\section{MATERIALS AND METHODS}

Bacterial Strains and Culture Conditions

$E$. faecalis ATCC 51299 and the clinical isolate $E$. faecalis 4437 were used. These bacteria were incubated in tryptic soy broth (TSB; Eiken Chemical Co. Tokyo, Japan) or TSB agar at $37^{\circ} \mathrm{C}$.

Antibiotic Susceptibility and Biofilm Formation

For the selection of each bacterial strain and transconjugant strain in the mixed culture, the antibiotic susceptibility of E. faecalis ATCC 51299 and E. faecalis 4437 was assayed in broth microdilution susceptibility tests to determine the minimum inhibitory concentration (MIC). For teicoplanin, an E-test (Aska Diagnostics, Inc., Tokyo, Japan) was used. Biofilm formation was measured using the procedure of Baldassarri et al. ${ }^{22}$ with some modifications. Sterile, flat-bottomed, 24-well polystyrene plates (Iwaki Co., Tokyo, Japan) were inoculated with $10 \mu \mathrm{l}$ of an overnight culture of E. faecalis in which $1 \mathrm{ml}$ of TSB or $1 \%$ glucose-TSB was dispensed in the wells. After $24-\mathrm{hr}$ incubation at $37^{\circ} \mathrm{C}$ without shaking, the wells were gently washed 5 times with $3 \mathrm{ml}$ of distilled water, dried in an inverted position, and stained with $500 \mu \mathrm{l}$ of $1 \%$ crystal violet solution for $15 \mathrm{~min}$. After staining, the wells were washed 5 times with tap water. Quantitative analysis of biofilm production was performed by adding $2.5 \mathrm{ml}$ of $95 \%(\mathrm{v} / \mathrm{v})$ ethanol to destain the wells. The optical density at $570 \mathrm{~nm}\left(\mathrm{OD}_{570}\right)$ of the ethanol solution was measured. Each assay was performed in triplicate. As a control, a noninoculated medium was used to determine background $\mathrm{OD}_{570}$.

Gelatinase and Cytolysin Assay — Production of gelatinase was detected using Todd-Hewitt agar (Difco Laboratories, Ann Arbor, MI, U.S.A.) containing 3\% gelatin. ${ }^{28)}$ The plated bacteria were incubated at $37^{\circ} \mathrm{C}$ overnight, and colonies surrounded by opaque zones were deemed gelatinase positive. Production of cytolysin (hemolysin) was determined on Todd-Hewitt agar supplemented with $5 \%$ horse blood. ${ }^{29)}$

Conjugational Transfer in Liquid Medium with or without Filtrated Medium of $E$. faecalis 4437

A medium containing culture filtrate was prepared as described by Dunny et al. ${ }^{30)}$ and a transconjugation experiment was carried out using the modified procedure of Andrup and Andersen. ${ }^{31}$ Twenty milliliters of fresh TSB was inoculated with $20 \mu \mathrm{l}$ of overnight culture of E. faecalis 4437 , and the material was incubated at $37^{\circ} \mathrm{C}$. At $\mathrm{OD}_{660}=1$, the supernatant collected by centrifugation was fil- 
trated through a membrane (pore size $0.22 \mu \mathrm{m}$ ) and then autoclaved. One milliliter of fresh TSB containing various concentrations $(0-50 \%)$ of the filtrated medium was dispensed into culture wells, and each well was inoculated with $10 \mu \mathrm{l}$ of $E$. faecalis ATCC 51299 culture $\left(\mathrm{OD}_{660}=0.6\right)$. After 120-min incubation at $37^{\circ} \mathrm{C}$ with shaking (300 rpm), $300 \mu \mathrm{l}$ of strain 4437 culture $\left(\mathrm{OD}_{660}=0.6\right)$ was added to each well and incubated for a further $60 \mathrm{~min}$ with shaking. The mixed cultures were diluted and plated on TSA plates supplemented with chloramphenicol $(15 \mu \mathrm{g} / \mathrm{ml})$ for selection of strain ATCC51299, tetracycline $(10 \mu \mathrm{g} / \mathrm{ml})$ for selection of strain 4437 , or gentamicin $(500 \mu \mathrm{g} / \mathrm{ml})$ and tetracycline $(10 \mu \mathrm{g} / \mathrm{ml})$ for selection of transconjugants. After incubation at $37^{\circ} \mathrm{C}$ for $48 \mathrm{hr}$, the number of colonies on each plate was counted. Transfer frequency was estimated as the number of transconjugants per number of ATCC51299 cells, or number of transconjugants per number of $E$. faecalis 4434 cells.

\section{Preparation and Analysis of Plasmid DNA}

Plasmid DNA from Enterococcus sp. was prepared according to the procedure of Woodford et al. ${ }^{32)}$ with some modifications. An overnight culture $(500 \mathrm{ml})$ of the strains was centrifuged, and the pellets were suspended in $10 \mathrm{ml}$ of suspending buffer [25\% sucrose in Tris-HCL $10 \mathrm{mM}$, EDTA $1 \mathrm{mM}$ (pH 8.0) (TE buffer) plus $10 \mathrm{mg}$ of lysozyme/ml]. After incubation at $37^{\circ} \mathrm{C}$ for $60 \mathrm{~min}, 15 \mathrm{ml}$ of alkaline-sodium dodecyl sulfate $(\mathrm{NaOH} 0.2 \mathrm{M}, 1 \%$ sodium dodecyl sulfate) was added and mixed gently. The mixture was incubated at $37^{\circ} \mathrm{C}$ for $30 \mathrm{~min}$. After the addition of $11.5 \mathrm{ml}$ of potassium acetate $3 \mathrm{M}$ ( $\mathrm{pH} 4.8$ ), the mixture was left on ice for $30 \mathrm{~min}$ and then centrifuged for $15 \mathrm{~min}$ at $4^{\circ} \mathrm{C}$. The supernatant was added to $25 \mathrm{ml}$ of $99 \%$ isopropyl alcohol and centrifuged at $3000 \mathrm{rpm}\left(4^{\circ} \mathrm{C}\right)$ for $30 \mathrm{~min}$. The precipitate was washed with $70 \%$ ethanol and dried. The dried precipitate was dissolved in TE buffer and subjected to $\mathrm{CsCl}$ density-gradient centrifugation. The plasmid DNA fraction was extracted with isopropyl alcohol and dialyzed in TE buffer overnight.

Digestion of the plasmid DNA was performed as recommended by the manufacturer. The digested plasmid DNA was electrophoresed through $0.7 \%$ agarose gel at $100 \mathrm{~V}$ for $1.5 \mathrm{hr}$. Tris-acetate $40 \mathrm{mM}$, EDTA $1 \mathrm{mM}$ (pH 8.0) (TAE buffer) was used for electrophoresis.

Transconjugation in Liquid Medium — Overnight cultures of the strain ATCC51299 and E. faecalis strain 4437 were mixed at ratios of $5: 1$, $2: 1,1: 1,1: 5,1: 10$, and $1: 50$, and $1 \mathrm{ml}$ of TSB was inoculated with $10 \mu \mathrm{l}$ of each mixture in roundbottomed polystyrene tubes (PS-tube, Iwaki Co.) and incubated at $37^{\circ} \mathrm{C}$ without shaking. At various time points, cells in the planktonic phase and in biofilms were isolated separately. To isolate cells in biofilm on the surface of the PS-tube, the tube was washed gently 5 times with $10 \mathrm{ml}$ of sterile water, and $0.5 \mathrm{ml}$ of saline was then added and vortexed with glass beads. Agar plates supplemented with appropriate antibiotics as described above were inoculated with cells recovered from the planktonic phase and the biofilms. After incubation at $37^{\circ} \mathrm{C}$ for $48 \mathrm{hr}$, colonies on the plates were counted, and the transfer frequency was estimated.

Transconjugation in Biofilm - Strain 4437 was grown in $1 \mathrm{ml}$ of TSB at $37^{\circ} \mathrm{C}$ for $18 \mathrm{hr}$ in a PStube without shaking. The biofilm formed in the PStube was washed as mentioned above, and $1 \mathrm{ml}$ of fresh TSB containing 2, 10, 20, or $100 \mu$ l of overnight culture of strain ATCC51299 was added. After incubation for $3,4.5,6$, and $9 \mathrm{hr}$ at $37^{\circ} \mathrm{C}$, cells from the planktonic phase and the biofilm were recovered. The number of transconjugants on the agar plates containing gentamicin $(500 \mu \mathrm{g} / \mathrm{ml})$ and tetracycline $(10 \mu \mathrm{g} / \mathrm{ml})$ was counted, and the transfer frequency was estimated as described above.

\section{RESULTS}

\section{Antimicrobial Susceptibility, Biofilm Formation, Gelatinase Activity, and Cytolysin Production of E. faecalis ATCC51299 and E. faecalis 4437}

E. faecalis ATCC51299 showed high-level resistance to streptomycin and gentamicin, resistance to erythromycin and chloramphenicol, and intermediate resistance to vancomycin, but was susceptible to teicoplanin, benzylpenicillin, ampicillin, and tetracycline. Strain 4437 showed resistance to tetracycline, but did not show high-level resistance to streptomycin and gentamicin, and was susceptible to vancomycin, teicoplanin, benzylpenicillin, and ampicillin (Table 1).

In strain ATCC51299, biofilm formation was not observed during incubation in TSB, but a significant increase was observed in TSB supplemented with $1 \%$ glucose (TSBG) $\left(\mathrm{OD}_{570}>2\right)$. Weak biofilm formation was observed in strain 4437 during incubation in TSB and TSBG $\left(\mathrm{OD}_{570}=0.3\right)$. Although Baldassarri et al. ${ }^{22)}$ and Tendolkar et al. ${ }^{33)}$ reported that biofilm formation of E. faecalis was strongly affected by the presence of glucose added in the 
Table 1. Susceptibility to Antibiotics, Biofilm Formation, and Gelatinase and Cytolysin Production in E. faecalis ATCC 51299 and 4437

\begin{tabular}{|c|c|c|c|c|c|c|c|c|c|}
\hline \multirow[b]{2}{*}{ Strain } & \multicolumn{9}{|c|}{$\mathrm{MIC}(\mu \mathrm{g} / \mathrm{ml})$} \\
\hline & $\mathrm{PC}$ & $\mathrm{ABPC}$ & CTRX & SM & GM & EM & AMK & $\mathrm{TC}$ & MINO \\
\hline ATCC 51299 & 2 & 1 & $>256$ & $>1024$ & $>512$ & $>256$ & $>256$ & 0.5 & $<0.13$ \\
\hline \multirow[t]{2}{*}{4437} & 2 & 1 & $>256$ & 64 & 8 & 0.5 & 64 & 128 & 16 \\
\hline & \multicolumn{5}{|c|}{$\mathrm{MIC}(\mu \mathrm{g} / \mathrm{ml})$} & Biofilm & Gel & Cly & \\
\hline Strain & $\mathrm{CP}$ & OFLX & REF & VCM & TEIC & $\left(\mathrm{OD}_{570}\right)$ & & & \\
\hline ATCC 51299 & 64 & 1 & 0.5 & 8 & 1.5 & $0.090 \pm 0.05$ & + & - & \\
\hline 4437 & 8 & 2 & 1 & 4 & 1.5 & $0.259 \pm 0.05$ & + & - & \\
\hline
\end{tabular}

MIC was measured according to the CLSI (formerly NCCLS) broth microdilution method, except for teicoplanin. The E-test was used for teicoplanin. Gel: gelatinase, formation of opaque zones around colonies on gelatin agar plate. Cyl: cytolysin, hemolysis on horse serum plate. Abbreviations: PC, benzylpenicillin; ABPC, ampicillin; CTRX, ceftriaxone; SM, streptomycin; GM, gentamicin; EM, erythromycin; AMK, amikacin; TC, tetracycline; MINO, minocycline; CP, chloramphenicol; OFLX, ofloxacin; REF, rifampicin; VCM, vancomycin; TEIC, teicoplanin.

Table 2. Effect of Culture Filtrate of E. faecalis 4437 on Plasmid Transfer from E. faecalis ATCC51299 to Strain 4437

\begin{tabular}{ccc}
\hline \hline Contentration of culture filtrate of strain 4437 in medium (\%) & Transconjugants/recipient & Transconjugants/donor \\
\hline 0.0 & $1.3 \times 10^{-5}$ & $8.1 \times 10^{-7}$ \\
3.1 & $9.3 \times 10^{-4}$ & $1.3 \times 10^{-4}$ \\
6.3 & $7.2 \times 10^{-2}$ & $5.2 \times 10^{-3}$ \\
12.5 & $1.6 \times 10^{-1}$ & $3.4 \times 10^{-2}$ \\
25.0 & $2.7 \times 10^{-1}$ & $4.8 \times 10^{-2}$ \\
50.0 & $2.5 \times 10^{-1}$ & $6.9 \times 10^{-2}$ \\
\hline
\end{tabular}

Culture filtrate was prepared from the culture broth of strain 4437 in the exponential phase. The filtrate was added to a mixed culture of strains ATCC51299 and 4437 at the designated concentrations.

medium, we did not observe this effect in biofilm formation by strain 4437 .

The formation of opaque zones around colonies of E. faecalis ATCC51299 and strain 4437 was observed on a gelatin medium (Table 1). Gelatinase, a secreted Zn-metalloprotease of E. faecalis, has been implicated as a virulence factor by epidemiologic data and in animal model studies, ${ }^{34)}$ and recent research has indicated that gelatinase is required for biofilm formation. ${ }^{24)}$ Cytolysin activity was not detected in either strain.

\section{Plasmid Transfer from E. faecalis ATCC51299 to Strain 4437 in Liquid Medium}

Positive clumping reactions were observed when the exponentially growing strain ATCC 51299 was mixed with a culture filtrate of strain 4437 and incubated for $120 \mathrm{~min}$ at $37^{\circ} \mathrm{C}$ with shaking. The clumping reaction was observed even in the culture containing $3.1 \%$ culture filtrate of strain 4437 (32fold dilution). Moreover, those positive clumping reactions were enhanced during 1-hr incubation with exponentially growing cells of strain 4437. Although clumping was not observed in cultures containing no culture filtrate of strain 4437, gentamicin- and tetracycline-resistant conjugants were present in the cultures. The number of colonies on the selective plates [gentamicin (GM) + tetracycline (TC)] increased as the content of strain 4437 culture filtrate was increased (Table 2).

Figure 1 shows the agarose gel electrophoresis of EcoRI-digested plasmid DNA isolated from colonies on the selective plates. Comparison of EcoRIdigested plasmid DNA fragments showed that at least four EcoRI-digested DNA fragments, indicated by arrowheads present in EcoRI-digested plasmid DNA isolated from strain ATCC51299, were also present in plasmid DNA fragments from colonies on the selective plates $(\mathrm{GM}+\mathrm{TC})$. Other EcoRI fragments observed in the EcoRI-digested plasmid DNA isolated from colonies on the selective plates were similar to those from strain 4437.

\section{Transconjugation Frequency in Liquid Medium}

Equal numbers of cells of strain ATCC51299 (donor strain) and strain 4437 (recipient strain) were mixed and incubated for $12 \mathrm{hr}$ at $37^{\circ} \mathrm{C}$. Time courses of the colony-forming units (CFU) of the donor strain, recipient strain, and transconjugant in the mixed culture were investigated (Fig. 2a and 2b). In 


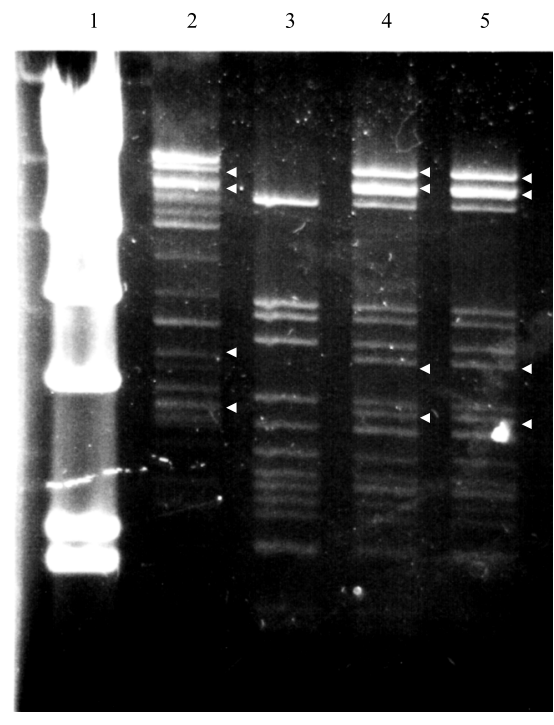

Fig. 1. Agarose Gel Electrophoresis of EcoRI-digested Plasmid DNA Isolated from E. faecalis ATCC 51299, Strain 4437, and Transconjugants

Whole plasmid DNA prepared from E. faecalis ATCC51299, 4437, and the transconjugants were digested with EcoRI and electrophoresed in $0.7 \%$ agarose (TAE buffer, $100 \mathrm{~V}$ ). Lane 1, HindIII-digested lambda DNA; 2, plasmid DNA from strain ATCC 51299; 3, plasmid DNA from strain $4437 ; 4,5$, plasmid DNA from randomly selected transconjugants. White arrowheads indicate the common DNA fragments in the digests of strain ATCC51299 and the transconjugants. the planktonic phase, viable cell counts of the donor and recipient strains increased until 4.5-hr incubation and plateaued at $10^{9} \mathrm{CFU} / \mathrm{ml}$. The number of transconjugants was $1.9 \times 10^{5} \mathrm{CFU} / \mathrm{ml}$ after 3 -hr incubation and reached a plateau at $1.1 \times 10^{6} \mathrm{CFU} /$ ml. In biofilm, the amount of strain 4437 and strain ATCC51299 was $8.1 \times 10^{5}$ and $1.1 \times 10^{4} \mathrm{CFU} / \mathrm{ml}$ after 3-hr incubation and increased to $10^{7}$ and $1.7 \times$ $10^{6} \mathrm{CFU} / \mathrm{ml}$, respectively. The amount of transconjugants in biofilm was $4.3 \times 10^{4} \mathrm{CFU} / \mathrm{ml}$ after $9-\mathrm{hr}$ incubation. The transfer frequencies (transconjugants per 4437 recipient) from strain ATCC51299 to the gentamicin-sensitive strain 4437 of the plasmid containing the gentamicin-resistant gene were $5.2 \times 10^{-4}$ in the planktonic phase and $4.4 \times 10^{-3}$ in biofilm.

We also investigated the effect of the ratio of donor cells (D) to recipient cells (R) on transconjugation. As shown in Fig. 3, a higher transfer frequency was observed at $4.5-\mathrm{hr}$ incubation in the planktonic phase and at 9-hr incubation in the biofilm. In the planktonic phase, transfer frequencies at ratios of $\mathrm{D}: \mathrm{R}=2: 1-1: 10$ were higher, and the highest transfer frequency $\left(4.3 \times 10^{-4}\right)$ was obtained at the ratio of $\mathrm{D}: \mathrm{R}=1: 1$. In the biofilm, the
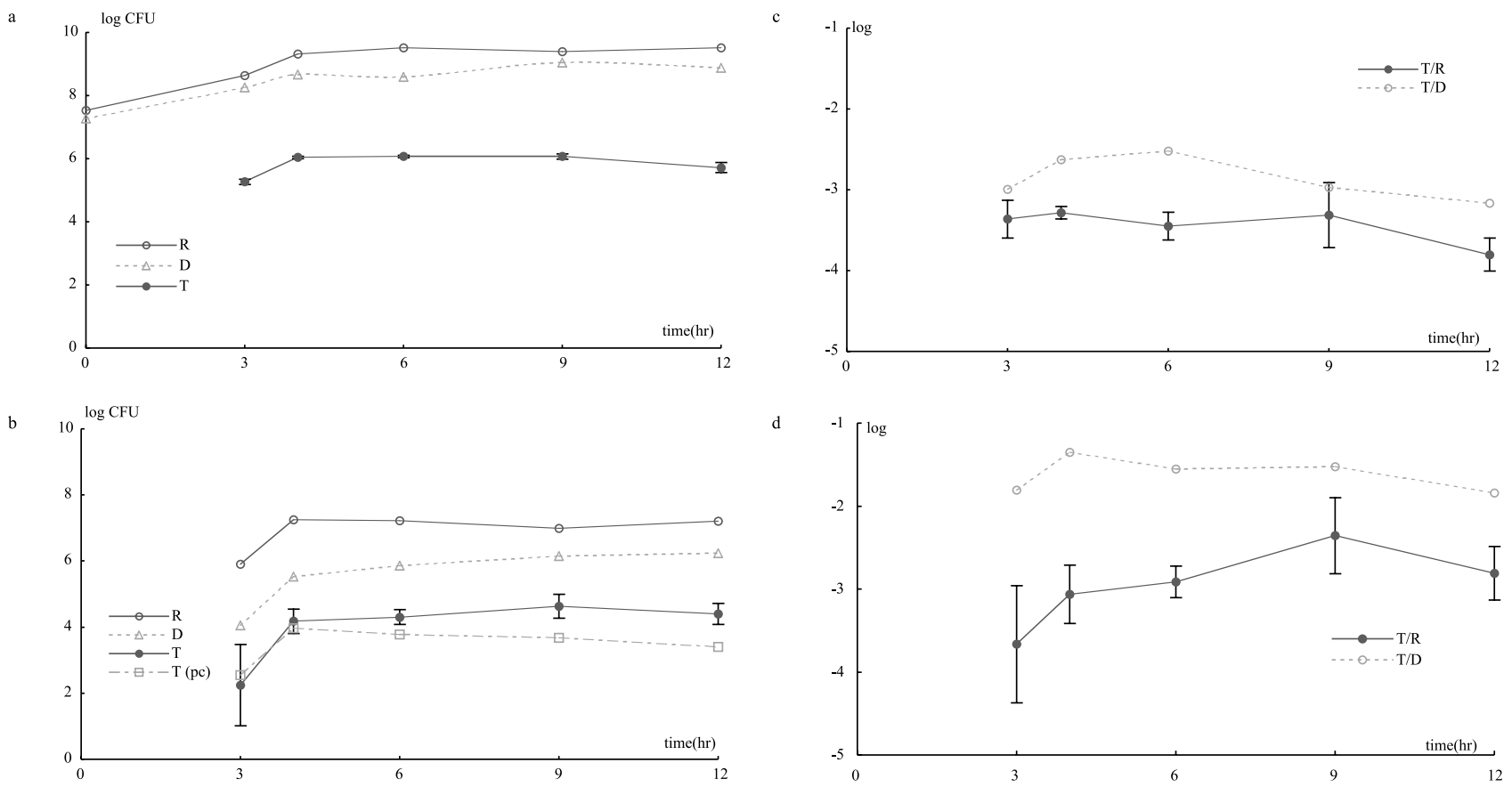

Fig. 2. Time Course of Donor and Recipient Cells and Transconjugants in the Planktonic Phase and in Biofilm

a, b, Time course of colony-forming units of donor, recipient, and transconjugant; c, d, Transfer frequencies of plasmid from ATCC51299 to 4437. a, c, Planktonic phase; b, d, Biofilm. D, ATCC51299 (donor); R, 4437 (recipient); T, transconjugant; T(pc), predicted CFU of T in biofilm was calculated as follows: $\mathrm{T}(\mathrm{pc})=\log \mathrm{CFU}$ of $[\mathrm{T}($ planktonic $) / \mathrm{R}\{($ planktonic) $) /($ biofilm $)\}]$. TSB was inoculated with equal cell counts of ATCC51299 (donor) and 4437 (recipient) and incubated at $37^{\circ} \mathrm{C}$. Viable cell counts of donor, recipient, and transconjugant cells were determined by counting colonies on the selective agar plates. CFUs and transfer frequencies were expressed as average \pm standard deviation (CFU of transconjugant and transfer frequencies $\mathrm{T} / \mathrm{R}$ ) from triplicate experiments. 


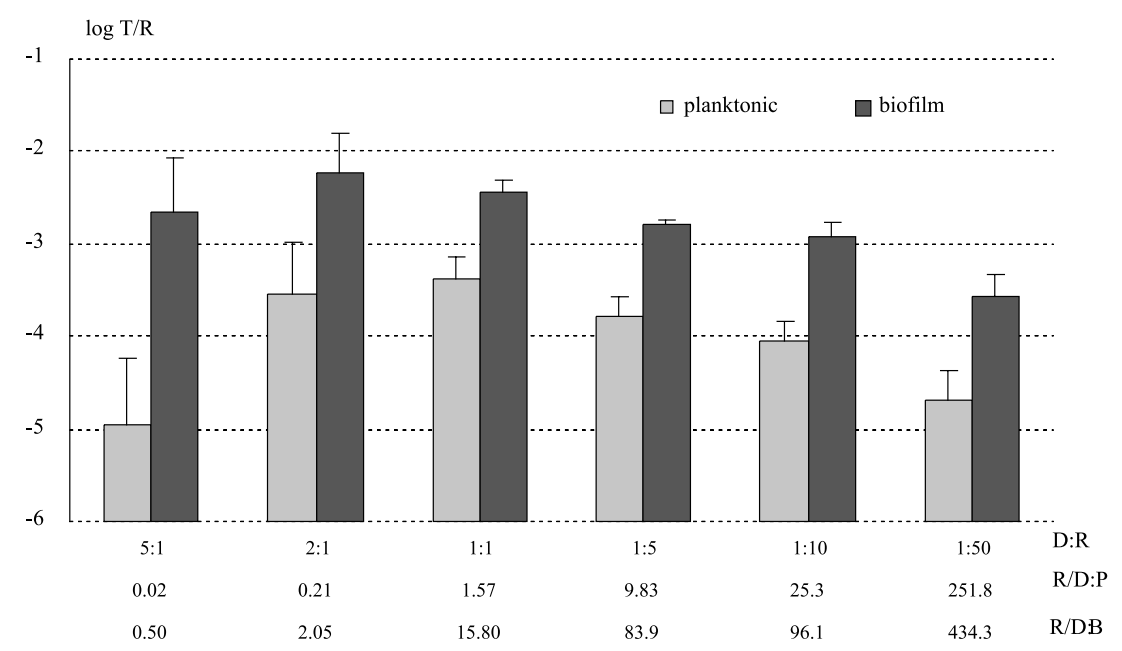

Fig. 3. Effect of Initial Ratio of Donor and Recipient Cells on Plasmid Transfer Frequencies in the Planktonic Phase and in Biofilm

Donor cells and recipient cells were mixed at various ratios in TSB and incubated at $37^{\circ} \mathrm{C}$. Transfer frequencies in the planktonic phase were determined after 4.5-hr incubation, and transfer frequencies in biofilm were determined after 9-hr incubation. Data shown are the averages of triplicate values. Standard deviations are indicated. D : R, R/D : P, and R/D : B indicate the ratio of donor cells to recipient cells before incubation, and after 4.5$\mathrm{hr}$ incubation in the planktonic phase and 9-hr incubation in the biofilm at $37^{\circ} \mathrm{C}$.

highest transfer frequency $\left(6.3 \times 10^{-3}\right)$ was obtained at the ratio of $\mathrm{D}: \mathrm{R}=2: 1$. The transconjugation frequency in the biofilm was higher than that in the planktonic phase at any $\mathrm{D}: \mathrm{R}$ ratio. For example, at $\mathrm{D}: \mathrm{R}=5: 1$ and $1: 1$, the transconjugation frequency in biofilm was 200- and 8-fold higher than that in planktonic phase, respectively. The transfer frequencies in the respective phases were also significantly different $(p<0.01)$.

\section{Transconjugation in Biofilm}

The plasmid donor strain E. faecalis ATCC51299 was added to an existing biofilm formed by the recipient strain E. faecalis 4437 at concentrations of $3.8 \times 10^{6}, 1.9 \times 10^{7}, 3.8 \times 10^{7}$, and $1.9 \times 10^{8}$, and the material was incubated at $37^{\circ} \mathrm{C}$ for $3 \mathrm{hr}$. Transconjugant cells, donor cells, and recipient cells were counted. The number of recipient cells in the biofilm was nearly constant $\left(1.8\right.$ to $\left.3.8 \times 10^{7} \mathrm{CFU} / \mathrm{ml}\right)$, but that of the donor strain ranged from $9.4 \times 10^{3}$ to 4.7 $\times 10^{5} \mathrm{CFU} / \mathrm{ml}$ (Fig. 4). The number of transconjugant cells and the transfer frequency (transconjugants per E. faecalis 4437 recipient) increased with increasing number of donor cells in the biofilm and was also correlated with the number of donor cells ( $r=0.99$ and 0.98 , respectively). In the planktonic phase, the number of donor cells was $7.8 \times 10^{7}$ to $3.9 \times 10^{9} \mathrm{CFU} / \mathrm{ml}$, but that of recipient cells and transconjugant cells decreased from $2.8 \times 10^{9}$ to 2.3 $\times 10^{8}$ and $2.1 \times 10^{5}$ to $5.3 \times 10^{4} \mathrm{CFU} / \mathrm{ml}$, respectively. When $1.9 \times 10^{8}$ cells of the donor strain were

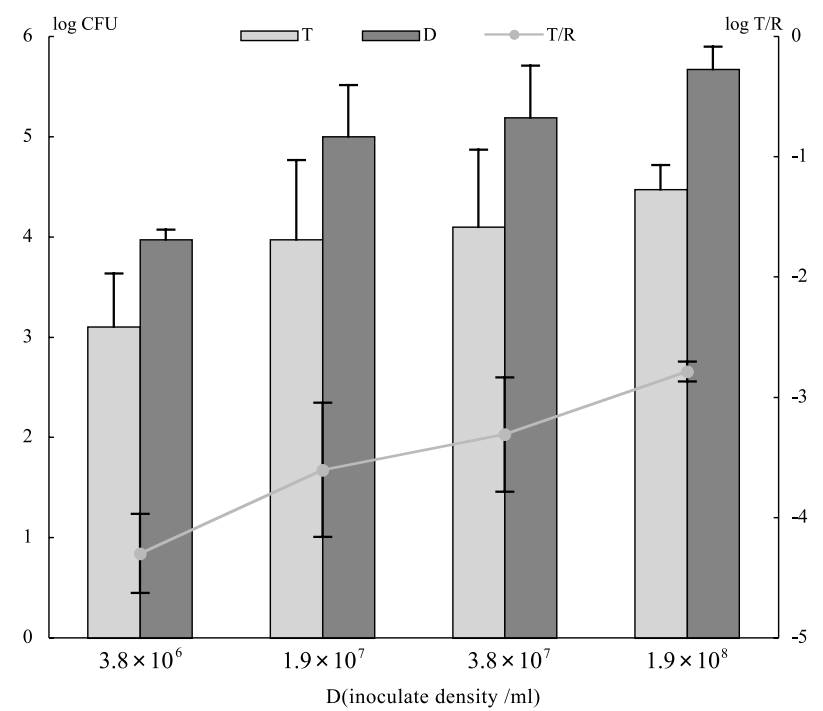

Fig. 4. Viable Cell Number of Donor Strain, Recipient Strain, and Transconjugant in the Existing Biofilm Formed by the Recipient Strain

E. faecalis 4437 was incubated for $18 \mathrm{hr}$ at $37^{\circ} \mathrm{C}$. The culture broth was removed and then $1 \mathrm{ml}$ of TSB and various numbers of $E$. faecalis ATCC51299 as indicated were inoculated. After 3-hr incubation, viable cells in the biofilm number were determined. Data shown are the averages of triplicate values. Standard deviations are indicated.

added to the biofilm, the transfer frequencies in the biofilm remained constant (1.6 to $\left.2.0 \times 10^{-3}\right)$ during 9-hr incubation, while the transfer frequencies in the planktonic phase decreased from $2.3 \times 10^{-4}$ (after 3-hr incubation) to $1.6 \times 10^{-5}$ (after 9-hr incubation). In all transconjugation experiments, no growth 
was observed on the transconjugant-selective plates when the parental cultures were plated.

\section{DISCUSSION}

High-frequency transfer of pheromone-response plasmids such as pAD1, pPD1, and pCF10 of enterococci in liquid media or on membrane filters is well known, ${ }^{11,30)}$ but little is known about plasmid transfer in biofilms formed by enterococci. We demonstrated that a plasmid containing the gentamicin resistance gene in E. faecalis ATCC51299 was transferred to E. faecalis 4437 clinically isolated in Japan. The transconjugants were detected not only in the planktonic phase (liquid medium) but also in biofilm on an abiotic (polystyrene) surface. Transconjugants were also detected in existing biofilms formed by the recipient strain 4437 when biofilms were inoculated with donor strain ATCC15299 after biofilm formation. In these biofilms, transfer frequencies (transconjugant cells per recipient cells or per donor cells) were higher than those in the planktonic phase.

Addition of culture filtrate prepared from an exponential growth phase culture of strain 4437 to E. faecalis ATCC51299 cultures produced a clumping reaction, and addition to a mixed culture increased plasmid transfer frequencies (Table 2). As is generally known, recipient strains of E. faecalis release a heat-stable substance (sex pheromone) which incites donor cells with specific conjugative plasmids to become adhesive, creating the cell-tocell contact required for plasmid transfer. Since donors themselves can be incited by recipient filtrates to "clump," such substances were termed "clumping-inducing agents" (CIAs), and filtrates with maximal CIA activity were found to have significant mating-enhancement activity. ${ }^{30)}$ It was speculated that some metabolites produced by strain 4437 act as pheromones to which plasmids of strain ATCC51299 respond, and the addition of the filtrate to strain 51299 induced a clumping reaction and increased the frequency of plasmid transfer.

The transconjugants obtained in the conjugation experiments showed antibiotic susceptibility equivalent to that of the parent strain 4437, except for highlevel resistance to gentamicin $(>500 \mu \mathrm{g} / \mathrm{ml})$. These transconjugants also demonstrated biofilm formation on a polystyrene surface, production of gelatinase, and nonproduction of cytolysin equivalent to that of the parent strain 4437 (data not shown).
An E. faecalis ATCC 51299 strain isolated at Barnes Hospital in the U.S.A. in 1989 carried vanB, $\operatorname{aac}\left(6^{\prime}\right)-1$ and $\operatorname{aph}\left(2^{\prime \prime}\right)$, ant(6)-I resistance genes responsible for its vancomycin- and high-level gentamicin- and streptomycin-resistant phenotype. This strain was used as a control in screening for highlevel aminoglycoside resistance in enterococci. ${ }^{35)}$ The $\operatorname{aac}\left(6^{\prime}\right)-1$ and $\operatorname{aph}\left(2^{\prime \prime}\right)$ genes are plasmid borne in most gentamicin-resistant isolates of $E$. faecalis ${ }^{36,37)}$ and conjugal transfer of aac $\left(6^{\prime}\right)-1$ and $a p h\left(2^{\prime \prime}\right)$ on the plasmid has been reported in enterococci. $^{36,38)}$ Our experimental results indicated that strain ATCC51299 harbored the plasmids containing the EcoRI fragments indicated by the arrowheads in Fig. 1 and that the plasmids have a gentamicinresistant gene. The results also suggest that the plasmid was transferred from E. faecalis ATCC51299 to strain 4437 by conjugation in the mixed culture and a high-level gentamicin resistance trait was imparted by $\operatorname{aac}\left(6^{\prime}\right)-1$ and $a p h\left(2^{\prime \prime}\right)$.

From a mixed culture of strain ATCC51299 and strain 4437, transconjugants were obtained not only from the planktonic phase but also from biofilm. Plasmid transfer by conjugation in the planktonic phase ended after 4.5-hr incubation. In the biofilm, however, the number of transconjugants increased gradually after 4.5 -hr incubation, making it necessary to consider the attachment of bacteria from the planktonic phase. We surmised that the higher transfer frequency in biofilm was a result of the attachment of transconjugants in the planktonic phase to the biofilm. Because the number of transconjugant cells in the planktonic phase and in the biofilm were equivalent to the number of recipient cells when incubated separately in the PS-tube containing TSB within $24 \mathrm{hr}$ (data not shown), we assumed that recipient cells and transconjugant cells in the planktonic phase attached to the surface of the biofilm at the same ratio. If transconjugants in the biofilm were derived from transconjugants in the planktonic phase, it is possible to estimate the number of transconjugant cells in the biofilm from the number of recipient cells in the planktonic phase and the biofilm. The result of this calculation indicated that the estimated number of transconjugants in the biofilm $(3.96 \pm 0.14)$ was similar to the number of transconjugants $(4.18 \pm 0.37)$ observed in the biofilm during 4.5-hr incubation, but after 6-hr incubation, the estimated number of transconjugants in the biofilm then falls below the actual number (Fig. 2b, broken line). If plasmid transfer ended within $4.5-\mathrm{hr}$ in the planktonic phase, increases in the number of 
transconjugants in the biofilm after 4.5-hr incubation should be deemed the result of transconjugation in the biofilm.

The frequency of plasmid transfer by transconjugation is reportedly influenced by the ratio of recipient to donor cells. ${ }^{39-41)}$ Similarly, in our results, the highest transfer frequencies were obtained in both the planktonic phase and the biofilm when the ratio of recipient cells to donor cells (R/D) was 1 to 2 . $R / D$ values in the biofilm were always higher than those in the planktonic phase.

Moreover, we demonstrated that transfer of the plasmid containing the gentamicin-resistant gene of strain ATCC51299 to strain 4437 occurred at a higher frequency in the existing biofilm formed by the recipient strain. In the biofilm, a correlation was observed between the number of donor cells and transconjugants, and between the number of donor cells and the ratio of transconjugants/recipient cells. In contrast, the ratio of transconjugants/donor cells was almost constant, as Astorga et al. ${ }^{40)}$ reported.

Hausner et al. ${ }^{25)}$ indicated that plasmid transfer occurred within biofilm at a high rate in the initial stages after donor introduction, that recipient cells existed in fixed locations in biofilm, and that high cell density probably assisted the initial formation of mating pairs when donor cells attached. When all initial recipients had received a plasmid, further plasmid transfer was markedly diminished, since the donor cells were also located in fixed locations. Christensen et al $^{42)}$ also observed a positive correlation between transconjugant establishment and the preexisting pool of recipient cells. The biofilm formed by recipient cells is regarded as one of the important factors for transconjugation in biofilm.

In the planktonic phase, however, the density of recipient cells decreased as the number of donor cells increased, and at the same time the number of transconjugants decreased. In biofilm, the fluctuation in recipient cell count was smaller, and the number of donor cells remained suitable for transconjugation, but this was not the case in the planktonic phase. This may be one of the reasons for the prolonged transconjugation observed in the biofilm, but not in the planktonic phase.

Biofilm provides an environment facilitating conjugation, such as minimal shear force and closer cell-to-cell contact. ${ }^{15)}$ The chance of random cell contact in an aqueous phase is greater than that in biofilm, but the relative spatial stability of organisms in biofilm should be favorable to conjugation. ${ }^{25}$ ) The dense community structure in biofilm increases plasmid release by conjugation, and the conjugation mechanism itself may enhance biofilm establishment. ${ }^{27)}$

In summary, we found that transfer of plasmids related to antimicrobial-resistant traits occurred more easily by conjugation on a material surface than in a liquid phase. Most bacteria found in nature live in biofilms on surfaces or at interfaces. The enterococci that cause superinfections can easily acquire a variety of antimicrobial-resistant genes from exotic environments/flora. Our results suggest that biofilms formed by enterococci on various surfaces give rise to efficient gene transfer among enterococci.

Acknowledgements We thank Professor Keiichi Hiramatsu and Professor Jun Igari for providing the strains used in this paper.

\section{REFERENCES}

1) Jett, B. D., Huycke, M. M. and Gilmore, M. S. (1994) Virulence of enterococci. Clin. Microbiol. Rev., 7, 462-478.

2) Murray, B. E. (1990) The life and times of the Enterococcus. Clin. Microbiol. Rev., 3, 46-65.

3) LeDell, K., Muto, C. A., Jarvis, W. R. and Farr, B. M. (2003) SHEA guideline for preventing nosocomial transmission of multidrug-resistant strains of Staphylococcus aureus and Enterococcus. Infect. Control Hosp. Epidemiol., 24, 639-641.

4) Vergis, E. N., Shankar, N., Chow, J. W., Hayden, M. K., Snydman, D. R., Zervos, M. J., Linden, P. K., Wagener, M. M. and Muder, R. R. (2002) Association between the presence of enterococcal virulence factors gelatinase, hemolysin, and enterococcal surface protein and mortality among patients with bacteremia due to Enterococcus faecalis. Clin. Infect. Dis., 35, 570-575.

5) Mundy, L. M., Sahm, D. F. and Gilmore, M. (2000) Relationships between enterococcal virulence and antimicrobial resistance. Clin. Microbiol. Rev., 13, 513-522.

6) Leclercq, R., Derlot, E., Duval, J. and Courvalin, P. (1988) Plasmid-mediated resistance to vancomycin and teicoplanin in Enterococcus faecium. N. Engl. J. Med., 319, 157-161.

7) Uttley, A. H., Collins, C. H., Naidoo, J. and George, R. C. (1988) Vancomycin-resistant enterococci. Lancet, 1, 57-58.

8) Gerberding, J. and CDC NNIS Personnel (2001) National Nosocomial Infections Surveillance (NNIS) System report: data summary from January 
1992-June 2001, issued August 2001. Am. J. Infect. Control, 29, 404-421.

9) Fujita, N., Yoshimura, M., Komori, T., Tanimoto, K. and Ike, Y. (1998) First report of the isolation of high-level vancomycin-resistant Enterococcus faecium from a patient in Japan. Antimicrob. Agents Chemother., 42, 2150.

10) Paulsen, I. T., Banerjei, L., Myers, G. S., Nelson, K. E., Seshadri, R., Read, T. D., Fouts, D. E., Eisen, J. A., Gill, S. R. and Heidelberg, J. F., et al. (2003) Role of mobile DNA in the evolution of vancomycin-resistant Enterococcus faecalis. Science, 299, 2071-2074.

11) Clewell, D. B. (1981) Plasmids, drug resistance, and gene transfer in the genus Streptococcus. Microbiol. Rev., 45, 409-436.

12) Costerton, J. W., Lewandowski, Z., Caldwell, D. E., Korber, D. R. and Lappin-Scott, H. M. (1995) Microbial biofilms. Annu. Rev. Microbiol., 49, 711-745.

13) O'Toole, G., Kaplan, H. B. and Kolter, R. (2000) Biofilm formation as microbial development. Annu. Rev. Microbiol., 54, 49-79.

14) Stanley, N. R. and Lazazzera, B. A. (2004) Environmental signals and regulatory pathways that influence biofilm formation. Mol. Microbiol., 52, 917924.

15) Donlan, R. M. and Costerton, J. W. (2002) Biofilms: survival mechanisms of clinically relevant microorganisms. Clin. Microbiol. Rev., 15, 167-193.

16) Dunne, W. M., Jr. (2002) Bacterial adhesion: seen any good biofilms lately? Clin. Microbiol. Rev., 15, 155-166.

17) Costerton, J. W., Stewart, P. S. and Greenberg, E. P. (1999) Bacterial biofilms: a common cause of persistent infections. Science, 284, 1318-1322.

18) Gander, S. (1996) Bacterial biofilms: resistance to antimicrobial agents. J. Antimicrob. Chemother., 37, 1047-1050.

19) Brooun, A., Liu, S. and Lewis, K. (2000) A doseresponse study of antibiotic resistance in Pseudomonas aeruginosa biofilms. Antimicrob. Agents Chemother., 44, 640-646.

20) Potera, C. (1999) Forging a link between biofilms and disease. Science, 283, 1837-1839.

21) Sandoe, J. A., Witherden, I. R., Cove, J. H., Heritage, J. and Wilcox, M. H. (2003) Correlation between enterococcal biofilm formation in vitro and medical-device-related infection potential in vivo. J. Med. Microbiol., 52, 547-550.

22) Baldassarri, L, Cecchini, R., Bertuccini, L., Ammendolia, M. G., Iosi, F., Arciola, C. R., Montanaro, L., Di Rosa, R., Gherardi, G. and Dicuonzo, G., et al. (2001) Enterococcus spp. produces slime and survives in rat peritoneal macrophages. Med. Microbiol. Immunol. (Berl.), 190, 113-
120.

23) Mohamed, J. A., Huang, W., Nallapareddy, S. R., Teng, F. and Murray, B. E. (2004) Influence of origin of isolates, especially endocarditis isolates, and various genes on biofilm formation by Enterococcus faecalis. Infect. Immun., 72, 3658-3663.

24) Hancock, L. E. and Perego, M. (2004) The Enterococcus faecalis fsr two-component system controls biofilm development through production of gelatinase. J. Bacteriol., 186, 5629-5639.

25) Hausner, M. and Wuertz, S. (1999) High rates of conjugation in bacterial biofilms as determined by quantitative in situ analysis. Appl. Environ. Microbiol., 65, 3710-3713.

26) Lilley, A. K. and Bailey, M. J. (1997) The acquisition of indigenous plasmids by a genetically marked pseudomonad population colonizing the sugar beet phytosphere is related to local environment conditions. Appl. Environ. Microbiol., 63, 1577-1583.

27) Molin, S. and Tolker-Nielsen, T. (2003) Gene transfer occurs with enhanced efficiency in biofilms and induces enhanced stabilisation of the biofilm structure. Curr. Opin. Biotechnol., 14, 255-261.

28) Zeng, J., Teng, F. and Murray, B. E. (2005) Gelatinase is important for translocation of Enterococcus faecalis across polarized human enterocytelike T84 cells. Infect. Immun., 73, 1606-1612.

29) Day, A. M., Cove, J. H. and Phillips-Jones, M. K. (2003) Cytolysin gene expression in Enterococcus faecalis is regulated in response to aerobiosis conditions. Mol. Genet. Genomics., 269, 31-39.

30) Dunny, G. M., Craig, R. A., Carron, R. L. and Clewell, D. B. (1979) Plasmid transfer in Streptococcus faecalis: production of multiple sex pheromones by recipients. Plasmid, 2, 454-465.

31) Andrup, L. and Andersen, K. (1999) A comparison of the kinetics of plasmid transfer in the conjugation systems encoded by the F plasmid from Escherichia coli and plasmid pCF10 from Enterococcus faecalis. Microbiology, 45, 2001-2009.

32) Woodford, N., Morrison, D., Cookson, B. and George, R. C. (1993) Comparison of high-level gentamicin-resistant Enterococcus faecium isolates from different continents. Antimicrob. Agents Chemother., 37, 681-684.

33) Tendolkar, P. M., Baghdayan, A. S., Gilmore, M. S. and Shankar, N. (2004) Enterococcal surface protein, Esp, enhances biofilm formation by Enterococcus faecalis. Infect. Immun., 72, 6032-6039.

34) Waters, C. M., Antiporta, M. H., Murray, B. E. and Dunny, G. M. (2003) Role of the Enterococcus faecalis GelE protease in determination of cellular chain length, supernatant pheromone levels, and degradation of fibrin and misfolded surface proteins. J. Bacteriol., 185, 3613-3623. 
35) Swenson, J. M., Clark, N. C., Sahm, D. F., Ferraro, M. J., Doern, G., Hindler, J., Jorgensen, J. H., Pfaller, M. A., Reller, L. B. and Weinstein, M. P., et al. (1995) Molecular characterization and multilaboratory evaluation of Enterococcus faecalis ATCC 51299 for quality control of screening tests for vancomycin and high-level aminoglycoside resistance in enterococci. J. Clin. Microbiol., 33, 3019-3021.

36) Hodel-Christian, S. L. and Murray, B. E. (1991) Characterization of the gentamicin resistance transposon Tn5281 from Enterococcus faecalis and comparison to staphylococcal transposons Tn4001 and Tn4031. Antimicrob. Agents Chemother., 35, 1147-1152.

37) Daikos, G. L., Bamias, G., Kattamis, C., Zervos, M. J., Chow, J. W., Christakis, G., Petrikkos, G., Triantafyllopoulou, P., Alexandrou, H. and Syriopoulou, V. (2003) Structures, Locations, and Transfer Frequencies of Genetic Elements Conferring High-Level Gentamicin Resistance in Enterococcus faecalis Isolates in Greece. Antimicrob. Agents Chemother., 47, 3950-3953.

38) Simjee, S., Manzoor, S. E., Fraise, A. P. and Gill,
M. J. (2000) Nature of transposon-mediated highlevel gentamicin resistance in Enterococcus faecalis isolated in the United Kingdom. J. Antimicrob. Chemother., 45, 565-575.

39) Licht, T. R., Christensen, B. B., Krogfelt, K. A. and Molin, S. (1999) Plasmid transfer in the animal intestine and other dynamic bacterial populations: the role of community structure and environment. $M i$ crobiology, 145, 2615-2622.

40) Fernandez-Astorga, A., Muela, A., Cisterna, R., Iriberri, J. and Barcina, I. (1992) Biotic and abiotic factors affecting plasmid transfer in Escherichia coli strains. Appl. Environ. Microbiol., 58, 392-398.

41) Bale, M. J., Day, M. J. and Fry, J. C. (1988) Novel method for studying plasmid transfer in undisturbed river epilithon. Appl. Environ. Microbiol., 54, 27562758.

42) Christensen, B. B., Sternberg, C., Andersen, J. B., Eberl, L., Moller, S., Givskov, M. and Molin, S. (1998) Establishment of new genetic traits in a microbial biofilm community. Appl. Environ. Microbiol., 64, 2247-2255. 